\title{
Hallazgos anatomopatológicos en fetos y neonatos bovinos del nordeste argentino
}

\author{
Lértora, W.J.; Sánchez Negrette, M.; Montenegro, M.A.; Villordo, G. \\ Cátedra de Patología General y Sistemática, Facultad de Ciencias Veterinarias, Universidad Nacional del \\ Nordeste, Sargento Cabral 2139, Corrientes (3400), Argentina. Tel/Fax: 0379-4425753. \\ E-mail: patgral@vet.unne.edu.ar.
}

\begin{abstract}
Resumen
Lértora, W.J.; Sánchez Negrette, M.; Montenegro, M.A.; Villordo, G.: Hallazgos anatomopatológicos en fetos y neonatos bovinos del nordeste argentino. Rev. vet. 23: 2, 126129, 2012. Se realizó necropsia y examen histopatológico a 26 fetos de abortos espontáneos y 13 neonatos bovinos. El 53,8\% de los fetos presentó lesiones inflamatorias; el 38,4\% no evidenció lesiones macro o microscópicas y el 11,5\% registró lesiones no inflamatorias (degeneración grasa hepática y onfalotoracópago). En los neonatos las principales lesiones fueron malformaciones congénitas (queilosquisis, palatosquisis, meningoencefalocele e hidrocefalia), onfaloflebitis y lesiones compatibles con parto distócico. El estudio determinó que la mayoría de los fetos abortados $(53,8 \%)$ presentaron lesiones inflamatorias en varios órganos, compatibles con las producidas por agentes infecciosos. Las causas de mortalidad neonatal correspondieron a malformaciones congénitas, distocias y onfalitis; estas últimas probablemente relacionadas con la falta de asistencia durante el parto y del ternero en los primeros días de vida.
\end{abstract}

Palabras clave: fetos y neonatos bovinos, examen macro y microscópico, Argentina.

\begin{abstract}
Lértora, W.J.; Sánchez Negrette, M.; Montenegro, M.A.; Villordo, G.: Pathologic findings in fetuses and bovine neonates in northeastern Argentina. Rev. vet. 23: 2, 126-129, 2012. Necropsy and microscopic examination was performed on 26 fetuses of spontaneous abortions and 13 bovine neonates. The $53.8 \%$ of fetuses showed inflammatory lesions, $38.4 \%$ revealed no macro or microscopic lesions, and $11.5 \%$ had non-inflammatory lesions (liver fatty degeneration and omphalo-thoracopagus). In neonates the main lesions were congenital malformations (cheiloschisis, palatoschisis, meningoencephalocele and hydrocephalus), omphalophlebitis and dystocia. The study found that most aborted fetuses (53.8\%) had inflammatory lesions consistent with infectious agents and the causes of neonatal mortality were congenital abnormalities, omphalitis and dystocia, the latter two being related to the lack of human assistance during calving and assistance to the calf in the first days of life.
\end{abstract}

Key words: bovine fetuses and neonates, macro and microscopic exam, Argentina.

\section{INTRODUCCIÓN}

La ganadería es la actividad preponderante en el uso actual de los suelos en la Provincia de Corrientes (Argentina). Sin embargo, este ganado se caracteriza por poseer una escasa eficiencia reproductiva, con bajos porcentajes de preñez, parición y marcación, sumado a altas pérdidas durante la preñez y el destete, así como largos intervalos entre pariciones ${ }^{1}$.

Recibido: 25 abril 2012 / Aceptado: 12 junio 2012

Proyecto SGCYT-UNNE B003/2008. Presentado en XXXII ${ }^{\circ}$ Sesión de Comunicaciones Científicas FCV-UNNE (Corrientes, Argentina) 2011.
Factores genéticos, nutricionales y de manejos reproductivo y sanitario contribuyen a esta baja eficiencia reproductiva. Los abortos y la mortalidad neonatal son importantes problemas sanitarios que provocan baja eficiencia reproductiva y grandes pérdidas económicas $^{6}$. Las causas de aborto son variadas e incluyen factores físicos-mecánicos, nutricionales, anomalías genéticas, hormonales, metabólicas e infecciosas ${ }^{3,4}$.

Las causales de abortos y mortalidad neonatal del bovino han sido ampliamente estudiadas en la pampa húmeda de Argentina, identificándose a Brucella abortus, Campylobacter fetus, Escherichia coli, virus diarrea viral bovina, Herpesvirus bovino-1 y Neospora caninum como las principales etiologías, mientras que 
los defectos congénitos y las distocias fueron las causas no infecciosas más comunes ${ }^{6,9,12}$. Sin embargo, las causas de aborto y mortalidad neonatal pueden variar según la región geográfica, posiblemente por diferencias climáticas, tipos de producción, programas sanitarios y prácticas de manejo ${ }^{6,7}$.

En el nordeste argentino la información es escasa. Solo un reporte informa que las principales pérdidas perinatales fueron ocasionadas por distocias y por agentes infecciosos, principalmente leptospirosis, herpesvirus bovino-1, brucelosis, virus diarrea viral bovina y campylobacteriosis ${ }^{7}$. El objetivo de esta comunicación fue reportar las lesiones anatomopatológicas observadas en fetos de abortos espontáneos y neonatos, a fin de incrementar la información regional que permita mejorar la eficiencia reproductiva de los bovinos del nordeste argentino.

\section{MATERIAL Y MÉTODOS}

El estudio fue realizado con fetos abortados espontáneamente, muestras de órganos fetales recolectados por veterinarios en el campo y neonatos remitidos al laboratorio de la cátedra de Patología General y Sistemática de la Facultad de Ciencias Veterinarias de la UNNE (Corrientes, Argentina), entre abril del 2003 y diciembre de 2011. Se realizó la necropsia completa de los fetos enteros y neonatos, determinándose el sexo y la edad gestacional aproximada mediante anamesis y/o fecha de inseminación.
Se obtuvieron muestras de bazo, timo, hígado, pulmones, corazón, riñones, músculo esquelético y encéfalo (cerebro, cerebelo, tubérculos cuadrigéminos anteriores, tubérculos cuadrigéminos posteriores, pedúnculos cerebelares y obex). Las muestras obtenidas fueron fijadas en formalina bufferada al 10\% durante 48 horas y procesadas para el examen histopatológico mediante la técnica clásica para bloques parafinados, cortadas a $5 \mu \mathrm{m}$ y coloreadas con hematoxilina-eosina. No se obtuvieron muestras para cultivos bacteriológicos ni virológicos.

\section{RESULTADOS Y DISCUSIÓN}

Se procesaron 39 especímenes bovinos, de los cuales 16 correspondieron a fetos enteros, 10 a órganos fetales recolectados por veterinarios y 13 fueron neonatos. Tres fetos procedieron de dos establecimientos lecheros de la Provincia de Corrientes y 23 fetos provinieron de 19 establecimientos de cría comercial del norte de las provincias de Santa Fe, Chaco y Corrientes. El sexo se determinó en 16/26 fetos, de los cuales 10 fueron hembras y 6 machos. La edad gestacional aproximada se determinó en 17/26 fetos: un feto se encontraba en el primer trimestre de gestación, 10 en el segundo y 6 en el tercero. El 61,5\% (16/26 fetos) se encontró en el segundo y tercer trimestre de gestación. En otros trabajos se detectó que la edad gestacional de los fetos abortados estaba influenciado por el muestreo, la mayoría de los fetos remitidos al laboratorio se encontraban en el

Tabla 1. Hallazgos anatomopatológicos en fetos y órganos fetales (no se incluyen los casos sin lesiones).

\begin{tabular}{|c|c|c|c|}
\hline $\mathrm{N}^{\circ}$ & espécimen & necropsia & histopatología \\
\hline 1 & feto & Placentitis necrotizante & Placentitis necrotizante \\
\hline 2 & feto & Imbibición hemoglobínica & $\begin{array}{l}\text { Encefalitis, miocarditis, hepatitis, neumonitis y nefritis no } \\
\text { purulenta multifocal }\end{array}$ \\
\hline 3 & feto & Sin lesiones aparentes & Miositis no purulenta multifocal \\
\hline 4 & feto & Sin lesiones aparentes & Bronconeumonía purulenta y encefalitis purulenta \\
\hline 5 & feto & $\begin{array}{l}\text { Hepatomegalia, meconio en } \\
\text { vías respiratorias }\end{array}$ & $\begin{array}{l}\text { Bronconeumonía purulenta, timitis y hepatitis con infiltrado } \\
\text { inflamatorio mixto }\end{array}$ \\
\hline 6 & feto & Sin lesiones aparentes & Miocarditis, hepatitis y miositis no purulenta multifocal \\
\hline 7 & feto & Sin lesiones aparentes & $\begin{array}{l}\text { Encefalitis, miocarditis, hepatitis y miositis no purulenta } \\
\text { multifocal }\end{array}$ \\
\hline 8 & feto & Momificado & $\begin{array}{l}\text { Meningitis no purulenta difusa y miositis no purulenta } \\
\text { multifocal }\end{array}$ \\
\hline 9 & feto & $\begin{array}{l}\text { Pericarditis y pleuritis } \\
\text { fibrinosa }\end{array}$ & $\begin{array}{l}\text { Meningitis, epicarditis, pleuritis y hepatitis no purulenta } \\
\text { difusa }\end{array}$ \\
\hline 10 & feto & onfalotoracópago & No realizada \\
\hline 11 & feto & Imbibición hemoglobínica & Sin lesiones aparentes \\
\hline 12 & feto & Imbibición hemoglobínica & Sin lesiones aparentes \\
\hline 13 & órganos fetales & No realizada & Esplenitis purulenta multifocal \\
\hline 14 & órganos fetales & No realizada & Bronconeumonía purulenta \\
\hline 15 & órganos fetales & No realizada & Placentitis necrotizante \\
\hline 16 & órganos fetales & No realizada & Encefalitis purulenta multifocal \\
\hline 17 & órganos fetales & No realizada & Encefalitis, miocarditis y hepatitis no purulenta multifocal \\
\hline 18 & órganos fetales & No realizada & Degeneración grasa microvacuolar hepática difusa \\
\hline 19 & órganos fetales & No realizada & Degeneración grasa microvacuolar hepática difusa \\
\hline
\end{tabular}


Tabla 2. Hallazgos anatomopatológicos en neonatos bovinos (no se incluyen los casos sin lesiones).

\begin{tabular}{cll}
\hline $\mathrm{N}^{\mathrm{o}}$ & necropsia & histopatología \\
\hline 1 & Palatosquisis & Sin lesiones aparentes \\
2 & Queilosquisis y palatosquisis & Sin lesiones aparentes \\
3 & Hidrocefalia & Hipoplasia cerebral y cerebelar \\
4 & Meningoencefalocele & Hipoplasia cerebral (Figura 1) \\
5 & Congestión, edema y hemorragia en cabeza y cuello & Congestión difusa encefálica, congestión pulmonar \\
6 & Congestión, edema y hemorragias en cabeza y cuello & Congestión difusa encefálica \\
7 & Onfalitis y peritonitis fibrinopurulenta & Meningitis, hepatitis y nefritis purulenta multifocal \\
8 & Cogestión y edema pulmonar & Neumonía intersticial aguda \\
9 & Onfaloflevitis y peritonitis fibrinopurulenta & Hepatitis y meningitis purulenta difusa \\
10 & Onfaloflevitis y peritonitis fibrinopurulenta. & Hepatitis, esplenitis y nefritis purulenta multifocal \\
\hline
\end{tabular}

tercer trimestre de gestación, ya que los fetos más grandes son más frecuentemente hallados en los sistemas de producción extensiva ${ }^{6,9}$.

El análisis anatomopatológico detectó $14 / 26$ fetos $(53,8 \%)$ con lesiones inflamatorias localizadas principalmente en encéfalo, corazón, pulmones, hígado, placenta y músculo esquelético. En 2/26 fetos (7,7\%) se registró degeneración grasa hepática. Un caso correspondió a gemelos unidos (onfalotoracópagos). En $9 / 26$ fetos $(38,4 \%)$ no se evidenciaron lesiones macro o microscópicas (Tabla 1).

Aunque no se realizaron estudios microbiológicos, el análisis histológico determinó que 14/26 fetos (53,8\%) presentó lesiones de posible origen infeccioso (encefalitis, miocarditis, bronconeumonía, hepatitis, miositis o placentitis). Además, cuatro de estos fetos presentaron asociación de encefalitis con focos de necrosis y gliosis, hepatitis y miocarditis no purulenta multifocal; estas lesiones, aunque no son específicas, sugieren neosporosis fetal ${ }^{2,5,8}$. Los resultados aquí obtenidos concuerdan con los de otros estudios donde informa que las causas infecciosas de abortos son significativamente mayores que las causas no infecciosas ${ }^{6,9}$.
En Argentina, las principales causas de abortos infecciosos son bacterias, representando el 22,6\% del total. Los agentes bacterianos más frecuentemente aislados fueron Brucella abortus, Campylobacter fetus y Escherichia coli $\beta$-hemolítico ${ }^{6,9}$. N. caninum es responsable de originar 7,3 a 9,9\% de abortos ${ }^{10,11}$. Los agentes virales (virus diarrea viral bovina y herpesvirus bovino-1) se diagnosticaron en $4,2 \%$ de fetos abortados y los agentes micóticos (Aspergillus) fueron los menos diagnosticados $(0,3 \% \text { de casos })^{6,9}$. A su vez, Leptospira interrogans serovariedad pomona fue la causa infecciosa de mayor incidencia entre las pérdidas perinatales, seguida por herpesvirus bovino-1, Brucella abortus, virus diarrea viral bovina y Campylobacter fetus ${ }^{7}$. Las causas no infecciosas de aborto más frecuentemente diagnosticadas en bovinos de la región pampeana son los defectos congénitos, distocias y momificaciones ${ }^{6}$, mientras que en la región del nordeste las distocias fueron la causa más frecuente ${ }^{7}$.

Los neonatos, 7 hembras y 6 machos, procedieron de 2 establecimientos lecheros de las provincias de Corrientes y Santa Fe y de 10 establecimientos de cría comercial de las provincias de Chaco y Corrientes. Los

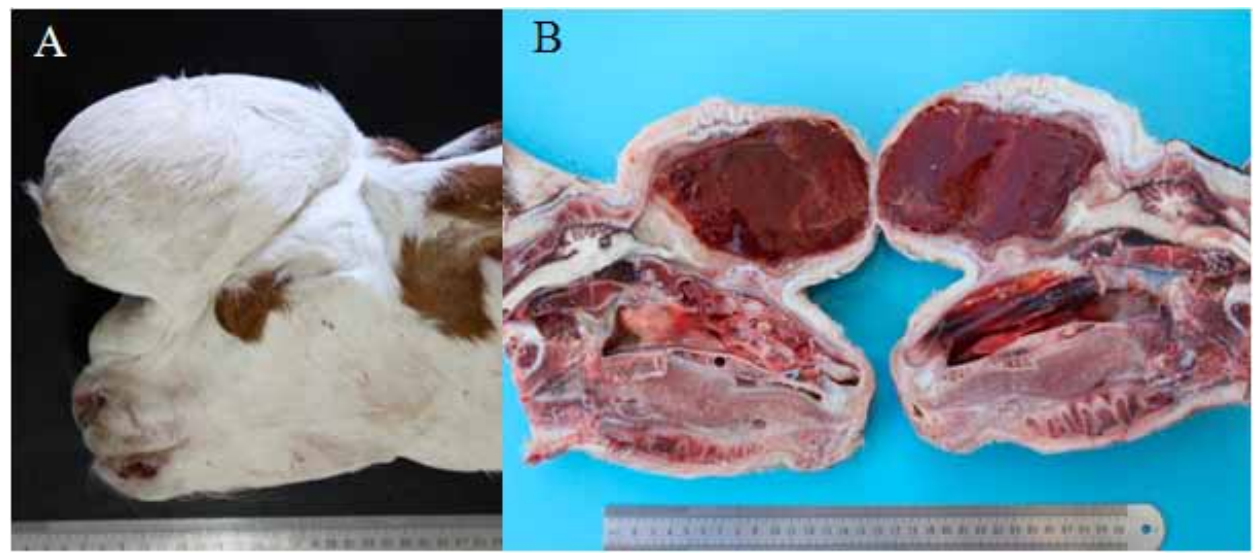

Figura 1. Meningoencefalocele en neonato. (A) Deformación de la región frontal del cráneo por tejido blando de forma semiesférica, de $16 \mathrm{~cm}$ de largo, $10 \mathrm{~cm}$ de alto y $11 \mathrm{~cm}$ de ancho. (B) Corte sagital del cráneo, se observa ausencia de huesos de la región frontoparietal y protrusión de la meninge con tejido nervioso. La meninge está en contacto con el tejido subcutáneo. Además, se aprecia severa dilatación de los ventrículos laterales con líquido cefalorraquídeo hemorrágico (hidrocefalia interna) con compresión de estructuras basales del encéfalo y corteza cerebral comprimida a una delgada capa de tejido hipoplásico. 
principales hallazgos anatomopatológicos fueron malformaciones congénitas (Figura 1), onfalitis con peritonitis fibrinopurulenta y lesiones compatibles con parto distócico (Tabla 2).

En el nordeste argentino las principales causas de mortalidad neonatal reportadas fueron distocias, onfalitis, inanición, traumatismos e hipotermia. Estas patologías están relacionadas con la falta de asistencia durante el parto, falta de atención del recién nacido e insuficiente vigilancia en los potreros de parición ${ }^{7}$. La distocia es una causa común de muerte perinatal en los rodeos de carne, donde ocasionan entre el 16,2 al 22\% de las pérdidas perinatales. Esta condición es más común en vaquillas de razas carniceras $6,7,9$.

En la región pampeana de Argentina, las principales pérdidas neonatales registradas son infecciones bacterianas septicémicas, siendo los agentes más frecuentemente aislados Escherichia coli, Brucella abortus, Arcanobacterium pyogenes y Salmonella sp. Por su parte, las anomalías congénitas son la causa no infecciosa más común de mortalidad neonatal ${ }^{9,12}$. En nuestra casuística, las anomalías congénitas diagnosticadas fueron: palatosquisis, queilosquisis, meningoencefalocele e hidrocefalia. Es difícil establecer el diagnóstico etiológico de dichas malformaciones. Pueden ser de etiología hereditaria (condrodisplasia, braquignatia, sindactilia o palatosquisis), infecciosa (Toxoplasma gondii, Neospora caninum o Pestivirus), físicas (hipertermia, traumatismos y compresiones), tóxicas (esteroides, parbendazole, organofosforados, tranquilizantes y vegetales teratogénicos como el lupino, cicuta y tabaco), nutricional (déficit de manganeso, iodo, vitamina $\mathrm{A}$, ácido fólico y cobre) y muchas anomalías aún son de causa desconocida ${ }^{6,9,12}$.

Se concluye que la mayoría de los fetos abortados $(53,8 \%)$ presentaron lesiones inflamatorias compatibles con agentes infecciosos, en tanto que las causas de pérdidas neonatales fueron malformaciones congénitas, onfalitis y distocias; estas dos últimas posiblemente relacionadas con la falta de asistencia durante el parto y durante los primeros días de vida del ternero. Los resultados del presente estudio aportan información acerca de las características de algunas patologías que afectan a los neonatos y fetos bovinos en nuestra región. No obstante, es necesario implementar estudios microbiológicos, serológicos y técnicas de biología molecular para determinar las causas de abortos y mortalidad neonatal; a fin de implementar programas sanitarios que permitan mejorar la eficiencia reproductiva del ganado bovino del nordeste argentino.

\section{REFERENCIAS}

1. Altamirano H, Macarrein O, Paredes H, Silva N. 2003. Análisis de la ganadería provincial. Evolución de la existencia bovina en Corrientes. Mem Sesión Comunic Cientif Tecn UNNE 2003 (Corrientes, Argentina): http://www. unne.edu.ar/Web/cyt/cyt/2003/comunicaciones/cyt.htm.

2. Anderson ML, Andrianarivo AG, Conrad PA. 2000. Neosporosis in cattle. Anim Reprod Sci 60: 417-431.

3. Anderson ML. 2007. Infectious causes of bovine abortion during mid- to late-gestation. Theriogenology 68: 474-486.

4. BonDurant RH. 2007. Selected diseases and conditions associated with bovine conceptus loss in the first trimester. Theriogenology 68: 461-473.

5. Campero CM, Anderson ML, Conosciuto G, Odriozola H, Bretscheneider G, Poso MA. 1998. Neospora caninum associated abortion in a dairy herd in Argentina. Vet Rec 143: 228-229.

6. Campero CM, Moore DP, Odeón AL, Cipolla AL, Odriozola E. 2003. Aetiology of bovine abortion in Argentina. Vet Res Comm 27: 359-369.

7. Draghi MG, Soni CA, Beckwith B, Zurbriggen MA, Homse AC, Rochinotti D, Alcaraz EL, Rizzi C, Caspe SG, Ramirez JC, Pereyra M, Biotti GM. 2006. Principales causas de mortalidad perinatal en bovinos en el nordeste argentino. Rev Med Vet 87: 140-143.

8. Dubey JP, Schares G. 2006. Diagnosis of bovine neosporosis. Vet Parasitol 140: 1-34.

9. Fernández ME, Campero CM, Morrell E, Cantón GJ, Moore DP, Cano A, Malena R, Odeón AC, Paolicchi F, Odriozola ER. 2007. Pérdidas reproductivas en bovinos causadas por abortos, muertes prematuras, natimortos y neonatos: casuística del período 2006-2007. Rev Med Vet 88: 246-254.

10. Moore DP, Campero CM, Odeón AC, Chayer R, Bianco MA. 2003. Reproductive losses due to Neospora caninum in a beef herd in Argentina. $J$ Vet Med B 50: 304-308.

11. Moore DP, Regidor J, Morrell E, Poso MA, Cano DB, Leunda MR, Linschinky L, Odeón AC, Odriozola E, Ortega LM, Campero CM. 2008. The role of Neospora caninum and Toxoplasma gondii in spontaneous bovine abortion in Argentina. Vet Parasitol 156: 163-167.

12. Morrell EL, Moore DP, Odeon AC, Poso MA, Odriozola E, Cantón G, Paolicchi F, Malena R, Leunda MR, Morsella C, Campero CM. 2008. Retrospective study of bovine neonatal mortality: cases reported from INTA Balcarce, Argentina. Rev Arg Microbiol 40: 151-157. 